\title{
ANALISIS KEANDALAN (RELIABILITY) PADA MESIN DIGESTER (STUDI KASUS : PT. SMART TBK BATU AMPAR MILL KOTABARU)
}

\author{
Dwi Mulyono Putro'), Qomariyatus Sholihah²) \\ 1,2Program Studi Tenik Mesin \\ Fakultas Teknik Universitas Lambung Mangkurat \\ JL. Akhmad Yani Km. 36 Banjarbaru, Kalimantan selatan, 70714 \\ Telp. 0511- 4772646, Fax 0511-4772646 \\ E-mail: mulyanadwi76@gmail.com
}

\begin{abstract}
Reliability is the application of design to the component so that the component can perform its function properly. Research conducted on Digester machine that its role is quite high at PT. SMART Tbk. Batu Ampar Mill, the method used is Reliability with MTTR Method. From the calculation results obtained Digester engine reliability value in 2015 has the highest reliability value of 0,8692 at the time of calculation 329,4 hours, And in 2016 has a reliability value of 0,2972 at the time of calculation of 389,45 hours. The value of digester machine reliability in 2015 is higher than in other years, this is evidenced that the life of the Digester machine in 2015 is more dominant than in year 2016. The higher the reliability value the better the machine used in the operation process.
\end{abstract}

Keywords: reliability, MTTR, and distribusi weibull.

\section{PENDAHULUAN}

Proses produksi yang optimal, menjadikan suatu produk yang dihasilkan oleh suatu industri dapat memiliki kualitas/mutu dan daya saing yang dapat diperhitungkan dalam persaingan pemasaran hasil produk baik didalam negeri maupun diluar negeri. Didalam mengimplementasikan suatu proses produksi agar lebih optimal, ada beberapa faktor yang mempengaruhi proses produksi tersebut. Dengan adanya hal tersebut, dapat menunjang aktivitas produksi dapat meningkatkan efisiensi dan efektifitas produksi, sehingga menghasilkan produk dengan harga yang mampu bersaing secara kompetitif. Oleh sebab itu industri atau perusahaan juga dituntut untuk mampu mengoptimalkan semua sumber daya yang dimiliki (Asmiati dan Abbas, 2014).

Mesin ialah satu dari beberapa faktor produksi yang paling utama supaya produk yang nanti dihasilkan menjadi maksimal, dengan jumlah sesuai kapasitas produksi mesin itu. Mesin mempunyai keandalan, yaitu peluang suatu komponen/sistem bisa bekerja sesuai fungsinya dalam jangka waktu yang telah ditetapkan. Langkah proses produksi mulai dari input kemudian proses operasi dan output, Agar proses produksi bisa terus berjalan membutuhkan suatu pemeliharaan pada mesin-mesin produksi itu sendiri. Menurut Assauri (1993), perawatan adalah kegiatan pemeliharaan pada fasilitas di pabrik setelah itu dilakukan perbaikan, penggantian dilakukan supaya keadaan operasi produksi sesuai dengan yang di inginkan. Hal ini dapat memperkecil suatu kemacetan, kemudian sistem bisa bekerja kembali dengan efisien. Tapi sering kali yang terjadi ialah ketika kelalaian dan perawatan baru dilakukan saat masalah sudah terjadi dalam sistem produksi sehingga menjadi banyaknya biaya perawatan tersebut. Jika melakukan perawatan secara teratur dan teliti dapat bermanfaat untuk menjamin masa pakai dari fasilitas produksi. 


\section{Digester}

Digester berasal dari kata digest yang berarti aduk, jadi yang dimaksud dengan Digester adalah suatu mesin yang digunakan untuk mengaduk atau melumatkan buah atau berondolan buah kelapa sawit (Loose Fruits) agar terbuka susunan serat pada daging buah, terpisah dari bijinya. Dengan cara memutar pisau yang dipasang pada dinding Digester dan digerakkan oleh motor listrik (Elektromotor).

Prinsip kerja mesin digester, yaitu:

Mesin dioperasikan terlebih dahulu dengan suhu $90^{\circ} \mathrm{C}-95^{\circ} \mathrm{C}$, kemudian suhu tersebut dialirkan kedalam tabung Digester melalui pipa masuk (Pipa Inlet), setelah suhu di dalam tabung merata, buah atau berondolan kelapa sawit dapat dimasukkan kedalam digester melalui pintu corongan mesin (Digester Dischorge).

Dengan adanya electromotor sebagai penggerak yang dihubungkan ke roda gigi reduser melalui kopling Flens dan selanjutnya daya putaran tadi diteruskan ke poros utama, sehingga poros utama hanya berputar, putaran poros utama adalah $1000 \mathrm{rpm}$, kemudian di rubah menjadi $25 \mathrm{rpm}$. Hal ini dikarenakan adanya roda gigi reducer yang dapat memperkecil putaran dengan perdandingan 1:40. Di dalam mesin tersebut buah atau berondolan kelapa sawit yang sudah terisi $\pm 90 \%$ dari kapasitas penuh diputar dengan menggunakan pisau yang di pasang pada poros utama, pisau pengaduk ini terdiri dari:
a. Long stirring arms
b. Short stirring arms
c. Bottom stirring arms

Di dalam digester juga dilengkapi dengan pisau tetap (Wall blades/fixed blades) yang berfungsi sebagai stator, sedang pisau yang berputar berfungsi sebagai rotor. Jadi buah atau berondolan kelapa sawit tidak diputar, melainkan dibenturkan dengan pisau tetap. Dengan adanya tangki pengaduk (Stirring Arms) dan tangki tetap (Fixed Arms) inilah buah atau berondolan kelapa sawit akan memecah atau membuka susunan serat pada daging buahnya dan juga melunakkan dengan sempurna, pada pengadukan ini akan keluar minyak kasar, lamanya pengadukan \pm 14-20 menit. Setelah buah atau berondolan kelapa sawit terlepas dari bijinya kemudian masuk dalam proses selanjutnya yaitu pengepressan (Screw Press).

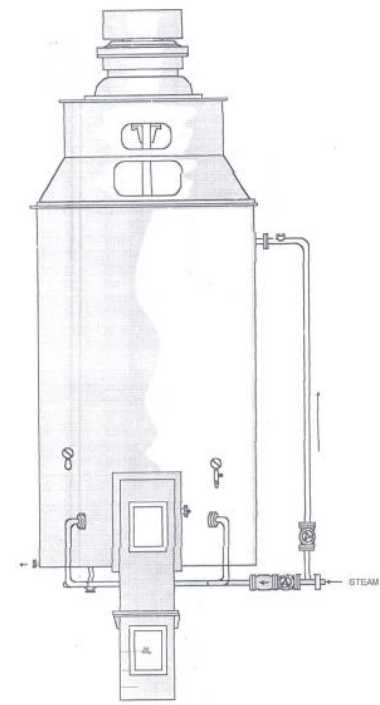

Gambar 1. Mesin Digester 


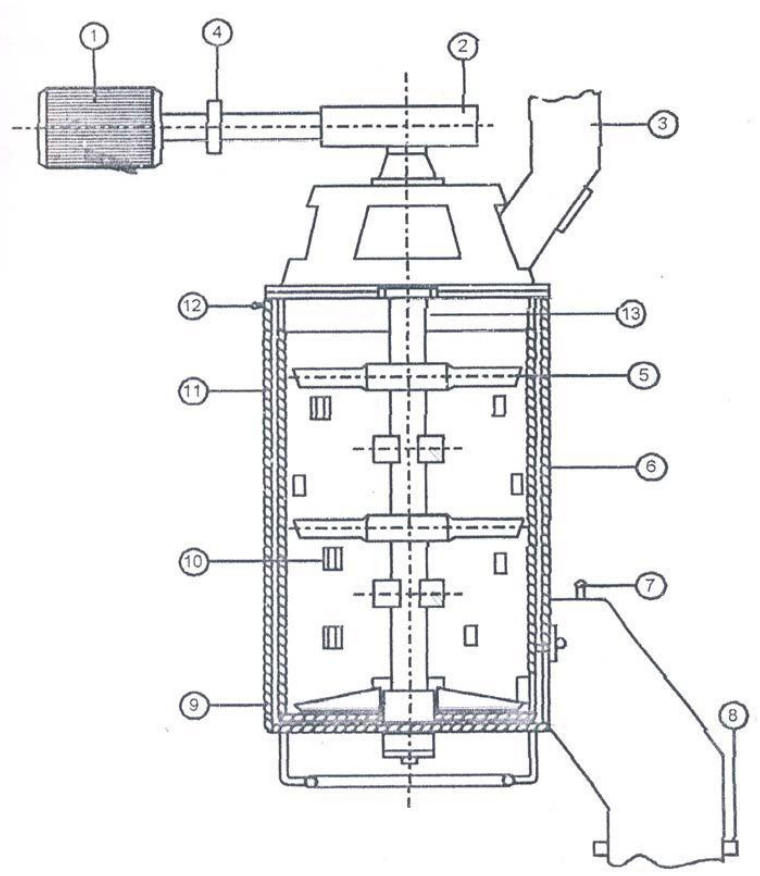

Gambar 2. Komponen Mesin Digester

Keterangan:
1. Electromotor
8. Saluran keluar
2. Roda gigi reducer
3. Saluran pemasukan
9. Bottom stirring arms
4. Kopling
10. Walls blades
11. Isolasi/plat pembungkus
5. Long stirring arms
12. System inlet pipa
6. Silinder luar
13. Poros utama
7. Hot water in

Fungsi masing-masing komponen mesin digester, yaitu:

1. Elektromotor

Berfungsi untuk merubah energi listrik menjadi energi mekanik yang berguna memutar shaft untuk pengadukan.

\section{Roda gigi reducer}

Berfungsi untuk mereduksi putaran timggi yang dihasilkan oleh electromotor menjadi putaran rendah pada poros utama.

\section{Saluran pemasukan}

Berfungsi untuk menggiring buah kelapa sawit ke dalam digester dari top distribution conveyor, choote harus diperhatikan pada saat beroperasi atau pada saat akan dioperasikan karena berondolan kelapa sawit tidak akan masuk ke dalam mesin digester.

\section{Kopling}

Berfungsi sebagai penerus putaran dan daya dari poros penggerak keporos yang digerakkan secara pasti, dimana sumbu kedua poros tersebut terletak pada suatu garis lurus. 
5. Long stirring arms

Berfungsi sebagai pemecah dan pengaduk buah kelapa sawit pada digester yang menggunakan 5 tingkat, stirring arms dipasang pada poros utama. Dalam penggunaan yamg normal pisau paling atas tidak layak dipakai bila kebanyakan pisau pengaduk, akan mengakibatkan pencernaan adukan yang berlebihan dapat menyebabkan:

a. Menambah kontaminasi biji dan minyak.

b. Menambah kerugian klarifikasi.

c. Menambah biaya perawatan.

d. Menambah kebutuhan daya.

6. Silinder/tabung

Berfungsi sebagai wadah/tempat di dalam proses pengadukan berjalan, tubuh silinder/tabung terbuat dari plat besi baja yang tahan aus dengan tebal 15 $\mathrm{mm}$.

7. Stem jacketed wall

Berfungsi untuk mengurangi panas yang terbuang dari silinder dengan ketebalan 7,5-10 cm.

8. Saluran pengeluaran

Berfungsi untuk menggiring buah kelapa sawit yang telah diaduk (diproses) menuju keproses pengepressan.

9. Bottom stirring

Fungsinya adalah selain pengaduk juga berfungsi sebagai pendorong buah kelapa sawit menuju chote pengeluaran, berjumlah 1 pasang dan terpasang pada poros utama dengan tingkat paling bawah.

10. Wall blades

Berfungsi untuk menahan buah kelapa sawit (Loose Fruits) dari pengadukan stirring arms agar pengadukan buah kelapa sawit lebih sempurna, wall blades dipasang pada dinding digester bagian dalam.

11. Plat pembungkus

Biasanya terbuat dari bahan yang tahan karat seperti: aluminium dan stainless steal. Karena biaya lebih murah, juga mengurangi berat dari kontruksi itu sendiri.

12. Steam inlet pipa

Berfungsi untuk memasukkan uap panas ke dalam mesin digester dengan tekanan $3 \mathrm{~kg} / \mathrm{cm}^{2}$. Untuk pengontrolan jumlah yang masuk pada mesin digester digunakan katup pengontrol yang di pasang pada pipa. Tujuan pemanasan ini adalah pemanasan yang akan digunakan untuk:

a. Mempermudah pengeluaran partikel-partikel minyak.

b. Mempermudah pengeluaran minyak.

c. Mempermudah pelepasan daging buah kelapa sawit.

d. Mempermudah proses pengepressan.

13. Poros utama

Poros utama terdiri dari dua bagian, satu pendek dan satu panjang. Poros ini disambung tegak lurus dengan poros reduction gearbox. Untuk poros yang 
panjang tersambung tegak lurus (sepusat) dengan poros yang pendek dengan menggunakan kopling flens, poros utama sebagai tempat pisau-pisau pengaduk.

\section{Keandalan}

Keandalan yaitu perencanaan pada sebuah komponen agar komponen tersebut dapat bekerja sesuai fungsi, tidak ada suatu kegagalan, sesuai dengan proses yang sudah ditetapkan. Adapun keandalan sebagai suatu kemungkinan bahwa sebuah sistem memiliki performansi yang diharapkan pada saat waktu dan kondisi operasi tersebut. (Dwi Priyanta, 2000).

Adapun Teori keandalan (reliability) yaitu kemungkinan (probabilitas) pada sebuah item supaya melakukan fungsi yang sudah ditetapkan, pada kondisi pengoperasian dan wilayah tertentu dalam periode waktu yang telah ditentukan. Probabiltas, yang merupakan komponen pokok pertama, merupakan input numerik bagi pengkajian keandalan sutau sistem yang juga merupakan indeks kuantitatif untuk menilai kelayakan suatu sistem. Pada beberapa kajian yang melibatkan disiplin ilmu keandalan, probabilitas bukan merupakan satu-satunya indeks, ada beberapa indeks lain yang dapat dipakai untuk menilai keandalan suatu sistem yang sedang dikaji.

Perawatan komponen yang diterapkan tidak bisa lepas dari pembahasan mengenai keandalan. Berdasarkan definisi keandalan dapat dikelompokan menjadi 5 komponen pokok sebagai berikut:

a. Probabilitas

Adalah komponen pokok utama, yaitu input numerik sebagai pengkajian Reliability pada sistem yang juga merupakan indeks kuantitatif untuk menilai layak tidaknya suatu sistem. Menandakan bahwa Reliability menyatakan kemungkinan bernilai 0-1. Indeks numerik 0 akan mendefinisikan suatu kejadian yang pasti tidak akan terjadi, sedang indeks numerik 1 akan mendefinisikan suatu kejadian yang pasti terjadi. Dari pengertian tentang konsep probabilitas diatas jelas terlihat bahwa sangat sedikit sekali kejadian yang mempunyai nilai probabilitas 0 atau 1 . Yang ada adalah hampir semua kejadian mempunyai nilai probabilitas antara 0 dan 1. Untuk keperluan teori keandalan, nilai probabilitas secara garis besar dapat dikelompokan menjadi dua keluaran yaitu keluaran yang mewaakiliii kejadian yang didefinisikan sebagai kejadian yang sukses, sedang keluaran yang lainnya mewakilii kejadian yang didefinisikan sebagai kejadian yang gagal. Bila ada lebih dari dua keluaran yang mungkin dari suatu event atau kejadian, maka keluaran itu dapat dikelompokan menjadi kelompok keluaran yang mewaakili kejadian yang sukses sedang sisanya bisa dikelompokan sebagai kejadian yang gagal.

b. Kemampuan yang diharapkan

Menandakan bahwa kriteria untuk dapat menyimpulkan tingkat kepuasan harus digambarkan secara jelas. Setiap unit memiliki standart untuk menentukan apa yang dimaksud dalam kemampuan yang diharapkan.

c. Tujuan yang diinginkan

Dimana untuk kegunaan peralatan harus spesifik dan jelas. Dikarenakan ada beberapa tahapan untuk memproduksi suatu barang konsumen.

\section{d. Waktu}

Komponen waktu adalah bagian yang dihubungkan dengan tingkat penampilan sistem, sehingga dapat menentukan suatu jadwal. Untuk Reliability memakai waktu yaitu: MTBF (Mean Time Between Failure), MTTF (Mean Time To Failure), MTTR (Mean Time To Repair). 
e. Kondisi Pengoprasian

Adapun faktor pada lingkungan seperti : getaran, kelembaman, untuk lokasi geografis yaitu kondisi suatu tempat berlangsungnya pengoperasian, adalah hal yang termasuk kedalam kondisi ini.

Keandalan dibedakan menjadi 2 sisi bagian yaitu sisi kualitatif dan sisi kuantitatif. Dimana perbedaan kedua sisi keandalan ini yaitu terletak pada parameter yang diinginkan. Keandalan kualitatif adalah kemampuan pembangkit dapat memenuhi konsumen terhadap energi yang dibangkitkan dalam periode waktu tertentu. Adapun keandalan kualitatif dibedakan menjadi 2 faktor yaitu faktor ketersediaan dan faktor kapasitas. Faktor ketersediaan yaitu perbandingan antara besarnya suatu daya yang tersedia terhadap daya yang terpasang dalam suatu sistem.

Faktor ketersediaan $=\frac{\text { Daya tersedia }}{\text { Daya } \text { terpasang }}$

Dalam faktor ketersediaan menggambarkan kesiapan saat operasi unit pembangkit pada sistem. Sehingga semakin tinggi faktor ketersediaan (100\%) maka diartikan bahwa semakin baik keandalan unit pembangkit. Faktor kapasitas yaitu menunjukkan besar sebuah unit pembangkit itut dimanfaatkan. Faktor kapasitas tahunan didefinisikan sebagai:

Faktor kapasitas $=\frac{\text { Produksi energi dalam } 1 \text { tahun }}{\text { Daya } \text { mampu } \times 8760 \text { jam }}$

Menurut Gunawan Eko Prasetyo (2007), Semakin tinggi faktor kapasitas maka semakin baik keandalannya. Keandalan kuantitatif yaitu metode analisa yang dilakukan dengan perhitungan matematis. Metode ini diperolehan melalui data perawatan (maintenance record) terhadap waktu kegagalan (time to failure) dan waktu untuk perbaikan (time to repair) dari suatu komponen atau sistem. Keandalan dari suatu komponen atau sistem adalah probabilitas untuk tidak mengalami kegagalan atau dapat beroprasi selama periode waktu (t). Data-data yang didapatkan akan diolah secara kuantitatif. Untuk data yang digunakan yaitu data maintenance data yang berupa data kegagalan dan perbaikan komponenkomponen mesin produksi. Pengolahan data secara kuantitatif tersebut menggunakan Software Minitab 17. Gunawan Eko Prasetyo (2007) yang menyatakan, langkah utama untukmenghitung keandalan komponenyaitumendapatkan data kegagalan komponen menggunakan distribusi statistik.

Manfaat Keandalan (Reliability)

Adapun manfaat keandalan yaitu untuk mendapatkan suatu informasi dengan basis dapat mendapatkan keputusan. Teori keandalan bermaksud memperkirakan suatu spare part mesin yang mengalami masalah, sehingga bisamenambah tingkat persediaan suku cadang mesin di gudang.

Adapun pemeriksaan digunakan supaya dapat mengetahui apakah sistem masih dalam keadaan baik/memenuhi syarat yang diinginkan atau tidak. Juga, dapat menjadwalkan perbaikan ketika komponen belum terjadi kerusakan atau breakdown.

Metode Analisis 

berikut:

Untuk menentukan teori Reliability digunakan 2 metode analisis sebagai

a. Metode Analisis Kualitatif

Metode Analisis Kualitatif adalah metode yang dilakukan menggunakan data pengalaman masa lalu.

b. Metode Analisis Kuantitatif

Metode Analisis Kuantitatif adalah metode menggunakan perhitungan, berupa data statistik.

\section{Pola Distribusi Reliability}

Untuk menentukan keandalan pada sistem yaitu faktor laju kerusakan dan waktu. Berikut adalah hubungan antara laju kerusakan dengan reliability dilihat Gambar 1.

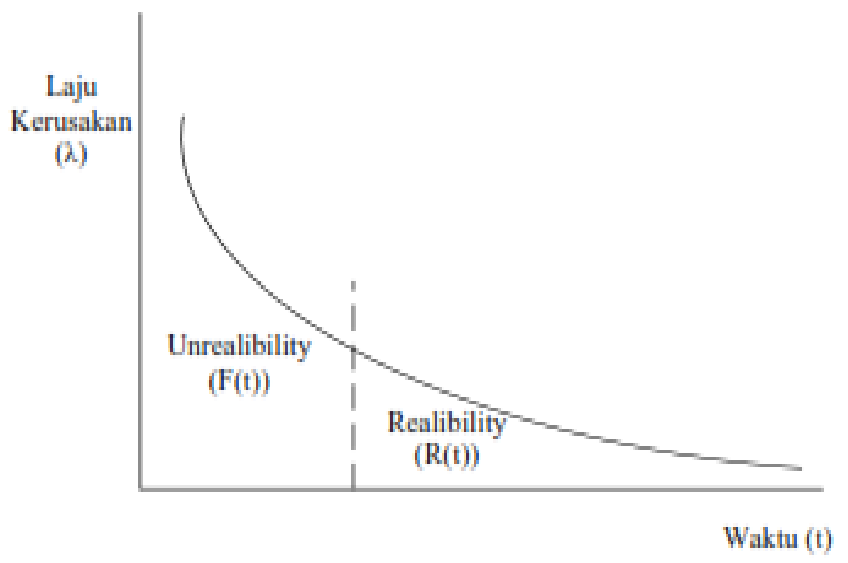

Gambar 1. Kurva Reliability

Gambar 1 menjelaskan bahwa dikatakan unreliability jika suatu alat atau mesin dengan laju kerusakannya tinggi dengan jangka waktu operasi mesin yang lebih pendek. Satuan pada laju kerusakan adalah kegagalan perwaktu. Dikatakan reliability apabila tingkat kerusakannya kecil dan waktu dalam pengoperasian suatu mesin/alat lebih panjang.

\section{MTTR (Mean Time to Repair)}

MTTR (Mean Time to Repair) ialah ukuran dasar maintainability diperbaiki item. MTTR Ini adalah rata-rata waktu yang dibutuhkan pada saat memperbaiki komponen yang gagal. Disajikan secara matematis, itu adalah untuk total pemeliharaan korektif waktu dibagi jumlah total tindakan pemeliharaan korektif selama periode waktu tertentu.

MTTR adalah waktu yang digunakan pada saat waktu perbaikan. MTTR untuk data berdistribusi Weibull dinyatakan dalam persamaan berikut:

MTTR $=\theta \cdot \Gamma\left(1+\frac{1}{\beta}\right)$

dimana:

MTTR = Rata-Rata Waktu Perbaikan (jam)

$t \quad=$ Waktu (jam)

$\Theta \quad=$ Parameter Bentuk dari distribusi weibull

$\beta=$ Parameter skala dari distribusi weibull

$\Gamma \quad=$ Fungsi Gamma, diambil dari tabel fungsi Gamma

METODOLOGI PENELITIAN 
Diagram alir dalam penelitian ini ditunjukkan dalam Gambar 2.

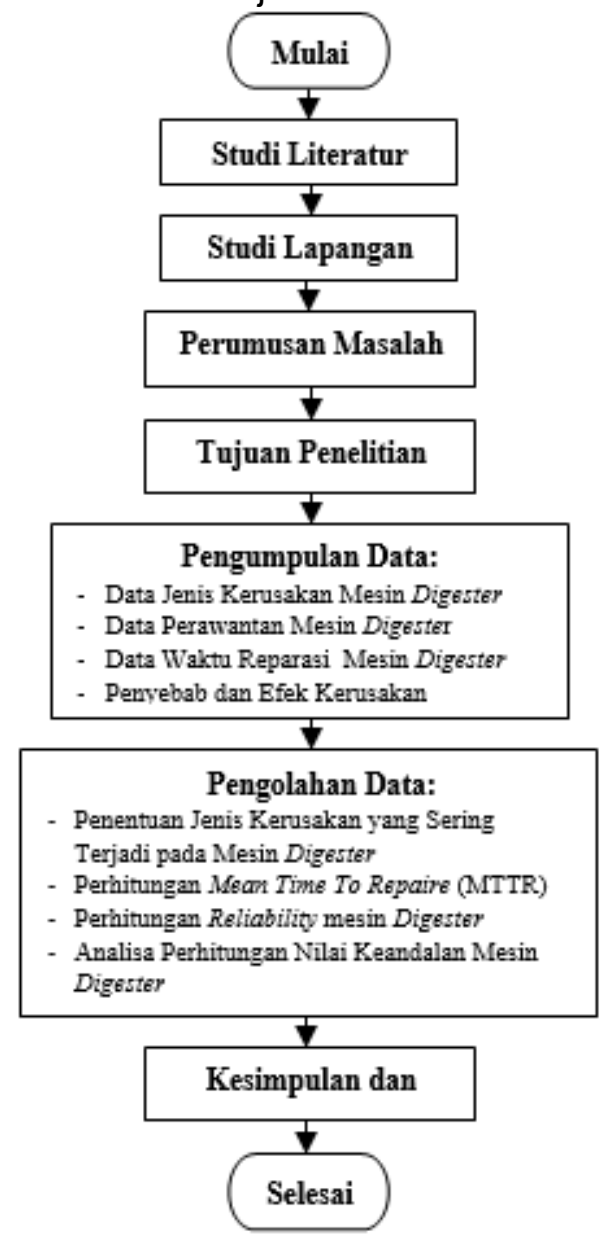

Gambar 2. Diagram Alir Penelitian

\section{PEMBAHASAN}

Berikut hasil dari perhitungan keandalan mesin Digester dari tahun 2015 sampai dengan tahun 2016 yang telah dikelompokan. Data hasil perhitungan dilihat dalam Tabel 1.

Table 1. Data keandalan menggunakan distribusi weibull

\begin{tabular}{|c|l|r|r|}
\hline No & \multicolumn{1}{|c|}{$\begin{array}{c}\text { Analisa } \\
\text { Keandalan }\end{array}$} & $\begin{array}{c}\mathbf{2 0 1 5} \\
(\mathbf{t}=\mathbf{3 2 9 , 4} \\
\text { jam})\end{array}$ & $\begin{array}{c}\mathbf{2 0 1 6} \\
(\mathbf{t}=\mathbf{3 8 9 , 4 5} \\
\text { jam})\end{array}$ \\
\hline 1 & CDF (\%) & 13,07 & 70.28 \\
\hline 2 & Reliability $(\%)$ & 0,8692 & 0.2972 \\
\hline 3 & Failure Rate & 0,001237 & 0.003429 \\
\hline 4 & Mean & 578,4283 & 308.5236 \\
\hline 5 & MTTR (jam) & 12,5146 & 14,3053 \\
\hline
\end{tabular}

Jika membandingkan nilai reliability tiap tahunnya, pada tahun 2015 nilai reliability dalam waktu 329,4 jam yaitu sebesar 0,8692 dalam persentasenya adalah 86,92\% dan pada tahun 2016 nilai reliability dalam waktu 389,45 jam sebesar 0,2972 dalam persentasenya adalah 29,72,\%. Dari hasil persentase tersebut dapat dibuktikan bahwa pada tahun 2015 nilai keandalan mesin Digester lebih baik dari tahun 2016 yaitu sebesar 86,92\%. 
Ditinjau dari Failure rate-nya pada tahun 2015 sebesar 0,001237 dan pada tahun 2016 sebesar 0.003429 . Disini berarti jika ditinjau dari failure rate-nya maka mesin Digester pada tahun 2015 lebih baik tingkat kegagalannya dibandingkan dengan tahun 2016. Dilihat dari Mean pada tahun 2015 mesin Digester dapat hidup rata - rata 578,4283 jam dan pada tahun 2016 mesin Digester dapat hidup rata - rata selama 308.5236 jam. Dapat disimpulkan bahwa rata - rata hidupnya mesin Digester tahun 2015 lebih baik dari tahun 2016.

Selanjutnya untuk nilai MTTR adalah rata - rata waktu perbaikan mesin Digester. Dapat dilihat pada tahun 2015 nilai MTTR mesin Digester yaitu sebesar 12,5146 jam dan pada tahun 2016 nilai MTTR mesin Digester yaitu sebesar 14,3053 jam. Dari data tersebut dapat disimpulkan bahwa MTTR mesin Digester pada tahun 2015 lebih tinggi dari pada tahun 2016. Mengapa MTTR mesin Digester 2016 lebih besar tingkat perbaikannya, karena jenis kerusakan yang terjadi pada tahun 2016 memerlukan waktu perbaikan yang lama yang dikarenakan lokasi perbaikannya berada didalam sehingga memerlukan waktu perbaikan yang lama.

Berikut ini adalah hubungan antara perhitungan data dan analisa yaitu sebagai berikut :

a. Analisa mesin digester tahun 2015

Hasil perhitungan diatas nilai CDF tahun 2015 menunjukkan hasil sebesar 0,1307 ini menunjukan bahwa nilai CDF relatif kecil maka semakin kecil nilai CDF maka persentase kerusakan mesin akan semakin kecil. Apabila nilai CDF nya kecil maka akan semakin besar tingkat reliabilitasnya, dengan tingkat Reliabilitas yang tinggi serta tingkat kegagalan yang kecil maka akan semakin tinggi rata - rata mesin Digester dapat hidup dengan nilai Mean sebesar 578,4283 jam. Dari sini nyatakan apabila Reliabilitas Mesin Tinggi dan tingkat kegagalannya rendah dengan rata-rata mesin hidupnya lama maka pada saat Mesin Digester terjadi failure maka tingkat rata-rata perbaikan Mesin Digester akan semakin tinggi. Dengan nilai rata-rata perbaikan Mesin Digester sebesar 12,5146 jam.

b. Analisa mesin digester tahun 2016

Hasil perhitungan diatas nilai CDF tahun 2016 menunjukkan hasil sebesar 0,7028 ini menunjukkan bahwa nilai CDF relatif besar maka semakin besar nilai CDF maka persentase kerusakan alat menjadi semakin besar. Apabila nilai CDF nya besar maka akan semakin kecil tingkat Reliabilitasnya, dengan tingkat reliabilitas mesin Digester sebesar 0,2972. Apabila nilai Reliabilitasnya kecil maka akan semakin besar tingkat kegagalan (Failure Rate) yang akan terjadi pada mesin. Tingkat kegagalan mesin Digester pada tahun 2016 sebesar 0.003429 kegagalan per waktu operasi selama 389,54 jam. Dengan tingkat Reliabilitas yang kecil dan tingkat kegagalan yang besar maka semakin kecil rata - rata mesin Digester dapat hidup yaitu dengan nilai Mean sebesar 308.5236. Dari sini apabila Reliabilitas Mesin kecil dan tingkat kegagalannya tinggi dengan rata - rata mesin hidupnya rendah, maka pada saat Mesin Digester terjadi failure, tingkat rata-rata perbaikan Mesin Digester akan semakin kecil. Sehingga nilai rata-rata perbaikan mesin Digester sebesar 14,3053 jam.

\section{Regulasi Untuk Perusahaan}

Adapun regulasi untuk perusahaan berdasarkan penelitian yang telah dilakukan, yaitu banyaknya komponen yang terdapat pada mesin Digester 
seharusnya selalu dilakukan pengecekan sebelum melakukan produksi agar dapat mengurangi terjadinya resiko kerusakan. Dari hasil penggolongan komponen dengan memperhatikan frekuensi kerusakan, maka didapatkan komponen yang sering mengalami kerusakan yaitu kerusakan pada komponen bearing, expeller dan kerusakan pada coupling. Kerusakan pada expeller diakibatkan bahan baku yang masuk tercampur dengan material - material yang mengakibatkan expeller mengalami kerusakan seperti potongan besi, batu dan kayu. Solusi yang dapat dilakukan adalah dengan lebih teliti melakukan pengecekan bahan baku sebelum masuk kedalam mesin Digester agar dapat mengurangi resiko rusak pada expeller. Kemudian kerusakan pada bearing terjadi diakibatkan karena kurangnya ketelitian mekanik dalam perawatan sehingga shaft/as menjadi goyang dan mengakibatkan bearing menjadi rusak.

\section{KESIMPULAN}

Kesimpulan dari penelitian ini adalah sebagai berikut:

1. Hasil penelitian pada mesin digester di PT. SMART Tbk Batu Ampar Mill menunjukan nilai keandalan pada tahun 2015 sebesar 0,8692 pada waktu perhitungan 329,4 jam dan tahun 2016 sebesar 0,2972 pada waktu perhitungan 389,45 jam. Dengan waktu perbaikan komponen yang mengalami kerusakan paling banyak ada 5 kali yaitu pada expeller dengan waktu total repair 70,40 jam dan Bearing 5 kali dengan total waktu repair 82,73 jam. Kerusakan pada expeller sering terjadi karena bahan baku yang masuk kedalam mesin tercampur dengan material lainnya seperti batu, biji kelapa sawitdan minyaknya yang dapat menyebabkan keausan pada komponen expeller.

2. Perbandingan nilai keandalan mesin digester tahun 2015 dan 2016 adalah sebagai berikut. Pada tahun 2015 memiliki nilai keandalan sebesar 0,8692, pada tahun 2016 memiliki nilai keandalan sebesar 0,2972. Data ini membuktikan bahwa nilai keandalan mesin Digesterpada tahun 2015 lebih tinggi dibandingkan dengan tahun 2016. Faktor utama nilai keandalan yaitu pada pamakaian mesin, apabila mesin ini dipakai lebih lama maka nilai keandalannya semakin besar atau mendekati 1 .

\section{DAFTAR PUSTAKA}

Abbas Hammada; Asmeati. 2014. "Analisis Total Preventive Maintenance dalam Meminimasi Downtime Tools Kritis dan Meningkatkan Reliability pada Mesin Finish Mill' Jurnal, Makassar.

Assauri, Sofyan. 1998. "Manajemen Produksi dan Operasi". Jurnal, Fakultas Ekonomi, Universitas Indonesia, Jakarta.

Priyanta Dwi. 2000. "Keandalan dan Perawatan". Modul. Institut Teknologi Sepuluh Nopemeber Surabaya. Surabaya.

Sachbudi Abbas Ras, dan andy Setiawan, 2010. "Analisa Keandalan Komponen Kritis Lift NPX-36000 Untuk Menentukan Jadwal Perawatan Pencegahan Yang Optimum" Skripsi, Jakarta.

Wahyu Nur Hidayat. 2015. "Analisis Keandalan Unit Dump Truck (Studi Kasus: PT.Pama Indo Mining)"Skripsi. Universitas Lambung Mangkurat, Banjarbaru 